\title{
Construct and Criterion Validity of the Postmenopause Sexuality Questionnaire-PMSQ
}

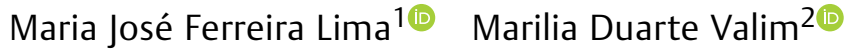 \\ ${ }^{1}$ Department of Gynecology and Obstetrics, Hospital Universitário \\ Júlio Muller, Cuiabá, MT, Brazil \\ ${ }^{2}$ School of Nursing, Universidade Federal de Mato Grosso, Cuiabá, \\ MT, Brazil \\ ${ }^{3}$ Department of Gynecology and Obstetrics, Faculdade de Ciências \\ Médicas, Universidade Federal de Mato Grosso, Cuiabá, MT, Brazil \\ Rev Bras Ginecol Obstet 2021;43(7):578.
}

Dear Editor,

In 2020, (RBGO 42:26-32,2020) we have published the article "Construct and criterion validity of the postmenopause sexuality questionnaire-PMSQ" (DOI: https://doi. org/10.1055/s-0040-1701461). Complete copies, in English and Portuguese, of the instrument were attached to be

\section{Editor-in-Chief Reply to the Authors}

Dear authors,

In response to your request, we are publishing, in the current issue of RBGO, the two versions (English and Portuguese) of the Postmenopausal sexuality questionnaire - PMSQ.

\author{
Sebastião Freitas de Medeiros ${ }^{3}$ ()
}

Address for correspondence Maria José Ferreira Lima, RN MSc, Hospital Universitário Júlio Muller, Cuiabá, MT, Brazil (e-mail: mariajosef.lima@gmail.com).

published as supplemental material. Nevertheless, the instrument was not published. Since we have been asked to send a copy of the questionnaire to some readers of RBGO, we ask you, if possible, to publish both versions of the instrument in RBGO as supplemental material of the article.
Complementary material is available.

Thank you for your contribution to RBGO.

\section{Marcos Felipe Silva de Sá}

Editor-in-chief RBGO received

June 15, 2021

accepted

June 16, 2021
DOI https://doi.org/

$10.1055 / \mathrm{s}-0041-1733910$

ISSN 0100-7203. (c) 2021. Federação Brasileira de Ginecologia e Obstetrícia. All rights reserved.

This is an open access article published by Thieme under the terms of the Creative Commons Attribution License, permitting unrestricted use, distribution, and reproduction so long as the original work is properly cited. (https://creativecommons.org/licenses/by/4.0/)

Thieme Revinter Publicações Ltda., Rua do Matoso 170, Rio de Janeiro, RJ, CEP 20270-135, Brazil 